Article

\title{
First Isolation and Characterization of Chryseobacterium cucumeris SKNUCL01, Isolated from Diseased Pond loach (Misgurnus anguillicaudatus) in Korea
}

\author{
Sang Guen Kim, Sib Sankar Giri $\oplus^{\circ}$, Sang Wha Kim, Jun Kwon, Sung Bin Lee and Se Chang Park* \\ Laboratory of Aquatic Biomedicine, College of Veterinary Medicine and Research Institute for Veterinary Science, \\ Seoul National University, Seoul 08826, Korea; imagine0518@snu.ac.kr (S.G.K.); giribiotek@gmail.com (S.G.G.); \\ kasey.kim90@gmail.com (S.W.K.); kjun1002@snu.ac.kr (J.K.); 1sbin1129@naver.com (S.B.L.) \\ * Correspondence: parksec@snu.ac.kr; Tel.: +82-2-880-1282
}

Received: 31 March 2020; Accepted: 18 May 2020; Published: 21 May 2020

check for updates

\begin{abstract}
Loaches are widely distributed throughout the natural environment and are consumed for medicinal purposes in East Asia. Usually, loaches are cultured in ponds where the water conditions can easily cause bacterial infections. Infections due to bacterial pathogens such as Aeromonas have been well described in cultured loaches; however, there is no report regarding Chryseobacterium infection. This study focused on the elucidation of the pathogenic and antibiotic resistance characteristics of C. cucumeris, SKNUCL01, isolated from diseased loaches (Misgurnus anguillicaudatus). SKNUCL01 forms a biofilm, which is associated with its virulence. Koch's postulates were satisfied with a lethal dose $50\left(\mathrm{LD}_{50}\right)$ of $8.52 \times 10^{7}$ colony-forming units $(\mathrm{CFU}) / \mathrm{ml}$. Abrasion facilitates the mortality of the fish, which makes it a possible infection route for C. cucumeris. The strain showed resistance to nearly all tested antibiotics, such as trimethoprim/sulfamethoxazole, levofloxacin, and ciprofloxacin, formerly considered effective treatments. Phenotypic analyses for antibiotic resistance-the combined disk test, double-disk synergy test, modified Hodge test, and efflux pump inhibition test—revealed that the resistance of SKNUCL01 originated from metallo-beta lactamases (MBLs) and efflux pumps. Our findings provide evidence that could result in a breakthrough against multidrug-resistant Chryseobacterium infection in the aquaculture industry; the antibiotic resistance-related genes can be elucidated through future study.
\end{abstract}

Keywords: loach; opportunistic pathogen; antibiotic resistance; $\beta$-lactamase; efflux pump

\section{Introduction}

Loaches (Misgurnus spp.) are widely distributed throughout natural freshwater environments such as rice paddy fields, streams, and reservoirs in Korea, China, and Japan [1-3]. Being rich in vitamins, proteins, and taurine, loaches are commonly referred to as "ginseng in the water" and are consumed for their nourishing and tonifying properties [4,5]. For these reasons, pond loaches (Misgurnus anguillicaudatus) are widely cultured in Korea and China as a food animal, yielding over 400,000 tons per year, which is $300 \%$ higher than the yield of gilthead seabream (Sparus aurata) and is comparable to that of the well-known channel catfish (Ictalurus punctatus) (Food and Agriculture Organization of the United Nations, 2016).

Usually, loaches are cultured in ponds, and the culture is often plagued by difficulties in controlling the water quality and stocking density. Such conditions can easily stress the fish, making them more vulnerable to various bacterial infections. Previously, infections with common bacterial pathogens such as Aeromonas, Flavobacterium, and Vibrio have been described in cultured loaches [6-9]. However, there 
is no report regarding Chryseobacterium infection in loaches, to the best of our knowledge. Recently, there has been an increase in clinical cases associated with isolates of Chryseobacterium spp. from different fish species. For instance, C. arthori was recovered from the kidney of pufferfish (Arothron hispidus) [10] and C. shigense was isolated from the liver, gill, and kidney of rainbow trout (Oncorhynchus mykiss) [11]. More recently, the pathogenicity of C. scophthalmum isolated from golden mahseer (Tor putitora) was confirmed [12]. Thus, the Chryseobacterium species are considered potential emerging pathogens in fish [13].

Chryseobacterium is notorious for multidrug resistance. In human cases, it has shown resistance against clinically important antibiotics, including cephalosporins and carbapenems [14-16]. There have been reports of treatment failures due to antibiotic resistance, leading to deaths $[17,18]$. The phenotypic antibiotic susceptibility testing and genotyping of the antibiotic resistance of the bacteria have also been well elucidated. However, only a few studies are available on the antibiotic susceptibility pattern of Chryseobacterium sp. isolated from diseased fish or associated environments [19-21]. In this study, we isolated C. cucumeris SKNUCL01 from diseased moribund loaches (M. anguillicaudatus). The pathogenicity and biofilm-forming capacity of the isolate were examined, and the antibiotic resistance mechanisms were inferred through phenotypic antibiotic susceptibility testing with or without specific inhibitors.

\section{Results}

\subsection{Isolation of Bacteria SKNUCL01}

A collection of fish, which included diseased fish with gross lesions on their skin, were brought to our aquatic animal facility. The animals were immersed in oxytetracycline hydrochloride $(50 \mathrm{mg} / \mathrm{L})$ for 5 days, without a positive result. This was followed by erythromycin $(25 \mathrm{mg} / \mathrm{L})$ treatment, but they failed to recover and eventually died. However, no mortality or morbidity was recorded in loaches without skin lesions. Only yellowish colonies were observed, except on skin samples that showed mixed colonies with dominant yellowish colonies. We isolated three bacterial strains from the post-mortem loaches; these were shiny, round, and yellowish colonies on tryptic soy agar (TSA) and produced a distinct odor. The straight short rod-shaped bacteria were negative to Gram staining.

\subsection{Histological Analysis of the Skin}

The histology of the skin of the naturally infected fish was examined and showed definite clinical signs, such as ulceration, loss of epidermis, and fungus-like white patches. A comparison was performed between normal skin and infected skin. The non-infected skin showed an intact epidermis and no signs of infiltration of inflammatory cells or red blood cells (Figure 1A), whereas epidermal exfoliation, damaged epithelial and club cells, inflammatory cell infiltration, and hemorrhage in the underlying dermal loose connective tissue were observed in the infected skin lesions (Figure 1B). 
(A)
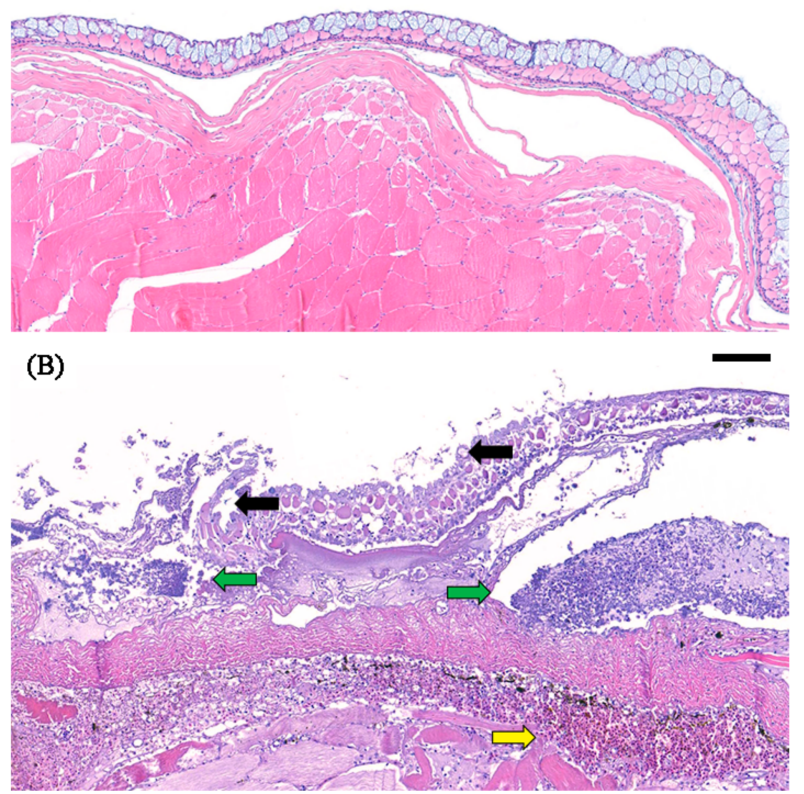

Figure 1. Histological analysis of the skin of a pond loach. (A) Normal skin with an intact epidermidis. (B) Infected skin with exfoliation of the epidermidis (black arrow), infiltration of inflammatory cells (green arrow), and hemorrhage (yellow arrow). Bar, $100 \mu \mathrm{m}$.

\subsection{Identification of Bacteria SKNUCL01}

The 16S rRNA gene sequencing revealed that the isolates shared $100 \%$ sequence homology and belonged to $C$. cucumeris. Although $16 \mathrm{~S}$ rRNA sequence comparisons using nucleotide basic local alignment search tool (BLASTn) could not specify the species in the genus Chryseobacterium, the sequence matched best with C. cucumeris (GSE06T) both in BLASTn and EZtaxon. Thus, the biochemical characteristics, using the VITEK 2 system (bioMérieux, France), were analyzed using closely related species: C. cucumeris (GSE06T), C. gleum (F93T), and C. indologense (RH 542T; Table S1). All three isolates showed the same pattern, and all the indices were homologous to C. cucumeris, whereas the isolates showed only 93\% (44/47) and 87\% (41/47) homology of biochemical indices with C. gleum, and C. indologense, respectively. As glucose non-fermenting bacteria, all Chryseobacterium showed negative at D-glucose. The main discrimination points between C. cucumeris and C. gleum were $\beta$-xylosidase, malonate, and glycline arylamidase. However, compared to $C$. indologense, tests for L-pyrrolydonyl-arylamidase, $\beta$-glucosidase, L-proline arylamidase, lipase, succinate alkalinization, and glycine arylamidase activities showed opposite results in C. cucumeris.

The phylogeny was examined with $16 \mathrm{~S}$ rRNA sequences, including an outgroup (A. hydrophila), and five sequences from environment, human, and fish isolates (Figure 2). The sequences showed clear clustering according to each isolated source, environment (red), human (green), and fish (blue), and the new isolate SKNUCL01 clustered with the environment group. The isolates were thus ultimately identified as C. cucumeris, and the $16 \mathrm{~S}$ rRNA sequences were deposited in GenBank under the accession number MK280733. 


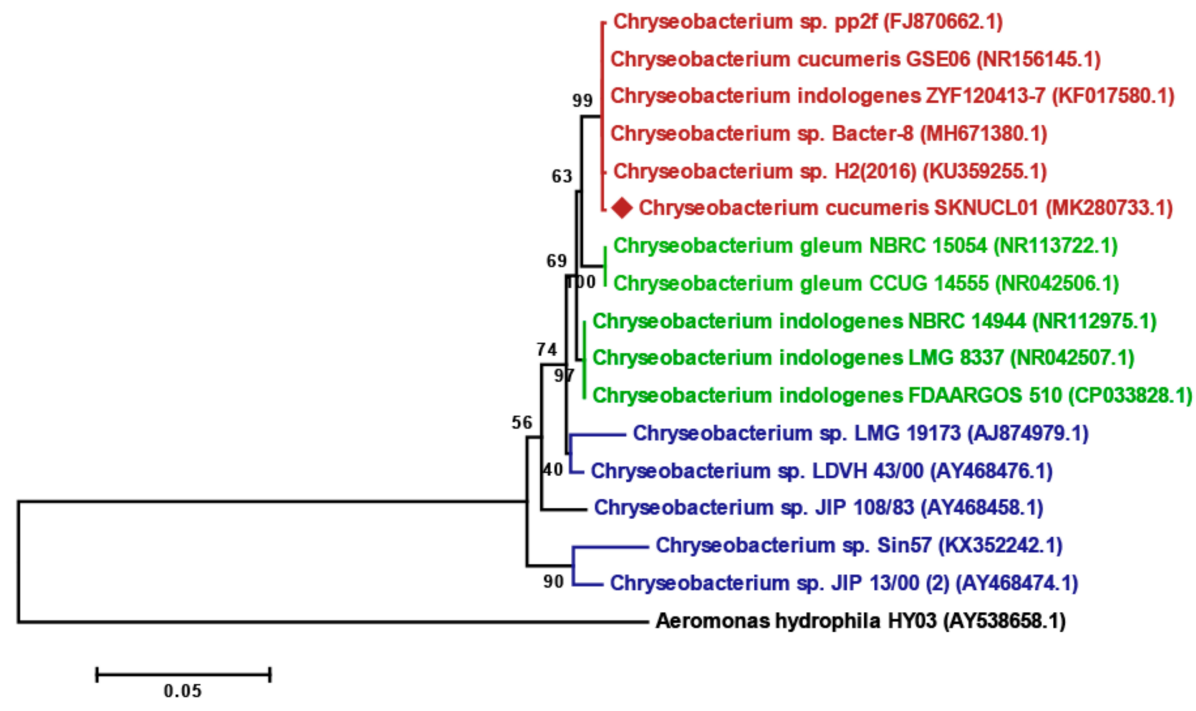

Figure 2. The phylogenetic tree based on partial 16S rRNA gene sequences, showing the relationship between C. cucumeris SKNUCL01 and related species in the genus Chryseobacterium. Bootstrap value based on a maximum-likelihood analysis of 1000 resamples. The sequence of Aeromonas hydrophila HY03 (AY538658.1) was used as an outgroup. Bar, 0.05 nucleotide substitutions per site.

\subsection{Virulence Test of SKNUCL01}

The virulence was analyzed by challenging the fish with the isolated bacteria by immersion or injection. The challenge by immersion was conducted with or without artificial abrasion. Without abrasion, the challenged fish were not affected by C. cucumeris even when the exposure time was increased by $24 \mathrm{~h}$. By contrast, with abrasion, the fish showed morbidity at 2 days post infection; mortality was detected after 5 days post infection, reaching up to 20\% (4/20). As shown in Figure 3, an intraperitoneal challenge revealed $5 \%$ mortality for $10^{5} \mathrm{CFU} /$ Fish (1/20; empty circle), $15 \%$ mortality for $10^{6} \mathrm{CFU} /$ Fish (3/20; filled triangle), $25 \%$ mortality for $10^{7} \mathrm{CFU} /$ Fish (5/20; empty triangle), and $65 \%$ mortality for $10^{8} \mathrm{CFU} /$ Fish (13/20; filled square). The calculated $\mathrm{LD}_{50}$ was $8.52 \times 10^{7} \mathrm{CFU} / \mathrm{ml}$. During the observation, lethargy, loss of appetite, and abnormal swimming were recorded from the infected fish. To confirm Koch's postulates, the bacteria were recovered from the liver and spleen as a pure isolate and identified as C. cucumeris.

The biofilm-forming property, associated with C. cucumeris virulence was observed in a polystyrene 96-well plate for $48 \mathrm{~h}$, and the optical density (OD) value was measured at $595 \mathrm{~nm}$; this was found to be $2.18 \pm 0.4$ and $3.31 \pm 0.34$ at 24 and $48 \mathrm{~h}$, respectively. 


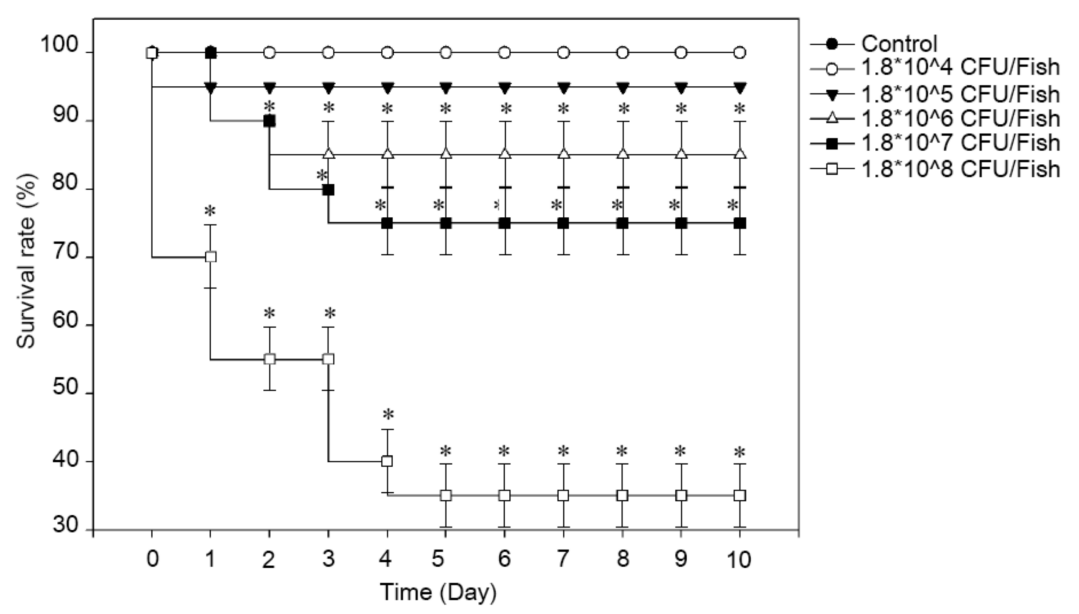

Figure 3. Pathogenicity of C. cucumeris SKNUCL01-challenged pond loach by intraperitoneal injection. Fish were infected with $C$. cucumeris SKNUCL01 at four different concentrations $\left(10^{5}\right.$ : empty circle, $10^{6}$ : filled triangle, $10^{7}$ : empty triangle, and $10^{8}$ : filled square). The fish injected with PBS served as the control group (filled circle). The mortality was recorded for a 10 day period after challenge. The values were presented as the mean from three independent experiments. The statistical significance was calculated using a one-way ANOVA with Bonferroni post-test.

\subsection{Antibiotic Susceptibility Test of SKNUCL01}

An antibiotic susceptibility test was conducted following the guideline of the Clinical and Laboratory Standards Institute (CLSI) M100; interpretive standards for other non-Enterobacteriaceae were used to determine the susceptibility of the isolated bacteria. C. cucumeris SKNUCL01 was resistant to ampicillin, ampicillin-sulbactam, cefotaxime, aztreonam, imipenem, meropenem, amikacin, gentamicin, ciprofloxacin, levofloxacin, and trimethoprim-sulfamethoxazole. It had intermediate resistance to piperacillin and minocycline and was susceptible to piperacillin-tazobactam, ceftazidime, and cefepime (Table 1).

Table 1. Antimicrobial susceptibility profiles of C. cucumeris SKNUCL01 by minimal inhibitory concentration.

\begin{tabular}{ccccc}
\hline \multirow{2}{*}{ Antimicrobial Agent } & \multicolumn{3}{c}{ Interpretation Range $^{\mathbf{a}}$} & \\
\cline { 2 - 4 } & $\mathbf{S ~}^{\mathbf{b}}$ & $\mathbf{I}$ & $\mathbf{R}$ & MIC $^{\mathbf{c}}$ \\
\hline Piperacillin & $\leq 16$ & $32-64$ & $\geq 128$ & 64 \\
Piperacillin/tazobactam & $\leq 16 / 4$ & $32 / 4-64 / 4$ & $\geq 128 / 4$ & $\leq 4 / 4$ \\
Ceftazidime & $\leq 8$ & 16 & $\geq 32$ & 4 \\
Cefepime & $\leq 8$ & 16 & $\geq 32$ & $\leq 1$ \\
Cefotaxime & $\leq 8$ & $16-32$ & $\geq 64$ & $\geq 64$ \\
Aztreonam & $\leq 8$ & 16 & $\geq 32$ & $\geq 64$ \\
Imipenem & $\leq 4$ & 8 & $\geq 16$ & $\geq 16$ \\
Meropenem & $\leq 4$ & 8 & $\geq 16$ & $\geq 16$ \\
Amikacin & $\leq 16$ & 32 & $\geq 64$ & $\geq 64$ \\
Gentamicin & $\leq 4$ & 8 & $\geq 16$ & $\geq 16$ \\
Minocycline & $\leq 4$ & 8 & $\geq 16$ & 8 \\
Ciprofloxacin & $\leq 1$ & 2 & $\geq 4$ & $\geq 4$ \\
Levofloxacin & $\leq 2$ & 4 & $\geq 8$ & $\geq 8$ \\
Trimethoprim/ & $\leq 2 / 38$ & - & $\geq 4 / 76$ & $\geq 4 / 76$ \\
sulfamethoxazole & & & &
\end{tabular}

a The interpretative criteria for other non-Enterobacteriaceae suggested by Clinical and Laboratory Standards Institute (CLSI) were used. ${ }^{\mathrm{b}} \mathrm{S}$ : sensitive; I: intermediate resistant; R: resistant. ${ }^{\mathrm{c}}$ MIC: minimum inhibitory concentration $(\mu \mathrm{g} / \mathrm{mL})$. 


\subsection{Phenotypic Screening for $\beta$-Lactamases}

To detect the $\beta$-lactamase that might affect the resistance of $C$. cucumeris SKNUCL01, phenotypic tests were performed using cephalosporins (ceftazidime, ceftriaxone, cefepime, and cefotaxime) and carbapenems (imipenem and meropenem). The combined disk test (CDT), double-disk synergy test (DDST), and modified Hodge test (MHT) were performed to detect metallo-beta lactamases (MBLs), serine penicillinases, and carbapenemases, respectively. In the CDT, cefotaxime and cefepime treatment showed a significant increase in the inhibition diameter, as shown in Table 2. In addition, the diameter increased in ceftriaxone $(2 \mathrm{~mm})$, meropenem $(2 \mathrm{~mm})$, and imipenem $(3 \mathrm{~mm})$. However, there were no changes when ceftazidime was combined with ethylenediaminetetraacetic acid (EDTA). In the DDST, co-treatment with amoxicillin-clavulanic acid showed no synergetic effect on the antibiotic disks examined (Table 2). Moreover, in the MHT, all of the results were negative for all antibiotics tested.

Table 2. Phenotypic tests for the detection of $\beta$-lactamases. Combined disk test (CDT), double-disk synergy test (DDST), and modified Hodge test (MHT) were performed to detect the metallo-beta-lactamase, serine penicillinases, and carbapenemases.

\begin{tabular}{lccc}
\hline & CDT $^{\mathbf{a}}$ & DDST $^{\mathbf{a}}$ & MHT $^{\mathbf{b}}$ \\
\hline Ceftazidime & 0 & 0 & - \\
Ceftriaxone & 3 & 0 & - \\
Cefepime & 8 & 0 & - \\
Cefotaxime & 18 & 0 & - \\
Imipenem & 3 & 0 & - \\
meropenem & 2 & 0 & -
\end{tabular}

a The results were analyzed in the increased diameter $(\mathrm{mm})$ of the inhibition zone. ${ }^{\mathbf{b}}$ The results were analyzed in the margin of the inhibition zone. Negative (-): circle shape; positive (+): clover shape.

\subsection{Phenotypic Screening for Efflux Pump against Antibiotics}

An efflux pump inhibitor, phenylalanine-arginine $\beta$-naphthylamide (PA $\beta N)$, did not inhibit the growth of C. cucumeris SKNUCL01 up to a concentration of $100 \mu \mathrm{g} / \mathrm{mL}$ (data not shown). The minimum inhibitory concentrations (MICs) of piperacillin and minocycline decreased upon treatment with $25 \mu \mathrm{g} / \mathrm{mL}$ PA $\beta N$. Further, $50 \mu \mathrm{g} / \mathrm{mL}$ of PA $\beta N$ treatment resulted in a decrease in imipenem and minocycline MICs and a significant decrease in the piperacillin MIC. The MICs of piperacillin, imipenem, and minocycline were significantly decreased (by four-fold) and in the case of ceftazidime, the MIC was decreased by two-fold with the treatment of $100 \mu \mathrm{g} / \mathrm{ml}$ of PA $\beta \mathrm{N}$ (Table 3).

Table 3. Effect of phenylalanine-arginine $\beta$-naphthylamide $(\mathrm{PA} \beta \mathrm{N})$ on the antimicrobial susceptibility profiles of C. cucumeris SKNUCL01.

\begin{tabular}{|c|c|c|c|c|}
\hline \multirow{2}{*}{ Antimicrobial Agents } & \multicolumn{4}{|c|}{ MIC } \\
\hline & Control & PAßN $25 \mu \mathrm{g} / \mathrm{mL}$ & $P A \beta N 50 \mu \mathrm{g} / \mathrm{mL}$ & $P A \beta N 100 \mu \mathrm{g} / \mathrm{mL}$ \\
\hline Piperacillin & 64 & 32 & $16^{*}$ & $8^{*}$ \\
\hline Piperacillin/tazobactam & $\leq 4 / 4$ & $\leq 4 / 4$ & $\leq 4 / 4$ & $\leq 4 / 4$ \\
\hline Ceftazidime & 4 & 4 & 4 & 2 \\
\hline Cefepime & $\leq 1$ & $\leq 1$ & $\leq 1$ & $\leq 1$ \\
\hline Cefotaxime & $\geq 64$ & $\geq 64$ & $\geq 64$ & $\geq 64$ \\
\hline Aztreonam & $\geq 64$ & $\geq 64$ & $\geq 64$ & $\geq 64$ \\
\hline Imipenem & $\geq 16$ & $\geq 16$ & 8 & $4^{*}$ \\
\hline Meropenem & $\geq 16$ & $\geq 16$ & $\geq 16$ & $\geq 16$ \\
\hline Amikacin & $\geq 64$ & $\geq 64$ & $\geq 64$ & $\geq 64$ \\
\hline Gentamicin & $\geq 16$ & $\geq 16$ & $\geq 16$ & $\geq 16$ \\
\hline Minocycline & 8 & 4 & 4 & $2 *$ \\
\hline Ciprofloxacin & $\geq 4$ & $\geq 4$ & $\geq 4$ & $\geq 4$ \\
\hline Levofloxacin & $\geq 8$ & $\geq 8$ & $\geq 8$ & $\geq 8$ \\
\hline Trimethoprim/sulfamethoxazole & $\geq 4 / 76$ & $\geq 4 / 76$ & $\geq 4 / 76$ & $\geq 4 / 76$ \\
\hline
\end{tabular}

* More than four-fold minimum inhibitory concentration (MIC) decrease. 


\subsection{Genetic Screening for Antibiotic Resistance}

Antibiotic resistance-related genes such as $\beta$-lactamase and, efflux pumps associated with the phenotypic resistance of SKNUCL01 were screened for further elucidation of the resistance mechanism. Since SKNUCL01 showed a positive result only in the CDT test for MBL phenotypic detection, we performed genetic screening for MBL genes, such as $b l a_{\mathrm{CIA}}, b l a_{\mathrm{CGA}}, F O X, b l a_{\mathrm{GES}}, b l a_{\mathrm{GIM}}, b l a_{\mathrm{IND}}, b l a_{\mathrm{KPC}}$, $b l a_{\mathrm{OXA}}$, and bla $a_{\mathrm{VIM}}$. In total, nine $\beta$-lactamase and 15 efflux pump genes related to antibiotic resistance were examined (Table S2). C. cucumeris SKNUCL01, a multiple antibiotic resistant strain, did not harbor any of the genes.

\section{Discussion}

Chryseobacterium cucumeris SKNUCL01 was isolated from a diseased loach from a local aquaculture farm that showed gross skin infection signs, such as ulcers on their skin, loss of the epidermis, or fungus-like white patches. A yellowish colony with a distinct odor was isolated from the skin, liver, and spleen of the infected loach. Because of this distinct odor, Chryseobacterium spp. have often been considered as food spoilage bacteria [22-24]. Recently, however, Chryseobacterium originally recovered from food products have been isolated from diseased animals $-C$. shigense from trout and $C$. oranimense from humans [11,25]. Likewise, C. cucumeris was originally isolated from the cucumber plant (Cucumis sativus) [26]. Based on the VITEK 2 bacterial identification test, the isolated strain was found to share biochemical characteristics with C. cucumeris. The $16 \mathrm{~S}$ rRNA gene sequence of the isolate most closely matched with C. cucumeris GSE06T (GenBank accession no. KX146463) in the EzBioCloud 16S database and was registered at GenBank under the accession number MK280733. This result suggests that the biochemical characteristics analyzed using VITEK 2 could be used to distinguish the Chryseobacterium genus at the species level.

Previously, from diseased loaches, bacterial diseases caused by Flavobacterium columnare [6], Vibrio cholera [7], Aeromonas hydrophila [8], A. sobria [9], Listonella anguilarum [27], and Shewanella putrifacience [27] have been reported; however, there has been no report of Chryseobacterium infection. There have been increasing reports of infections caused by this organism, which are related to diseased farmed fish, including C. aahli from lake trout [28], C. indologenes from yellow perch [29], and C. piscicola from salmonid fish [30]. The gross clinical signs caused by Chryseobacterium are ulcerative skin lesions and severe systemic infection. Similarly, the major clinical sign of the fish infected by C. cucumeris SKNUCL01 was skin ulcers, which presumably caused mortality.

A virulence study was conducted using intraperitoneal injection and bath immersion with or without artificial abrasion on the skin. The injection method revealed that the C. cucumeris SKNUCL01 strain, with an $\mathrm{LD}_{50}$ of $8.52 \times 10^{7} \mathrm{CFU} / \mathrm{ml}$, was pathogenic to the pond loach. In the immersion without abrasion method, neither mortality nor morbidity was detected; there was no increase in mortality even after prolonged exposure $(\sim 24 \mathrm{~h})$ to bacteria. In contrast, immersion with artificial skin abrasion showed a $20 \%$ mortality at the concentration of $6 \times 10^{7} \mathrm{CFU} / \mathrm{ml}$ after exposure to bacteria for $1 \mathrm{~h}$. These results support the general observation of opportunistic pathogens that the infection could be encouraged by the abrasion on the fish body [31,32].

The exact virulence factor has not been fully explored for Chryseobacterium; however, the production of biofilm and protease were suggested as potential virulence factors [33]. C. cucumeris SKNUCL01 can form a biofilm at the air-liquid interface rather than on the side and bottom of the polystyrene plate (Figure S1). The $\mathrm{OD}_{595}$ value for detecting a biofilm was above 3.0 after $24 \mathrm{~h}$ of incubation; this value indicates that the bacterium is a strong biofilm former, based on the criteria of Snoussi et al. [34].

The major concern related to Chryseobacterium infection is its antibiotic resistance. The organisms isolated from human clinical sources are generally resistant to beta-lactams and carbapenems. Similarly, over $90 \%$ of the bacteria isolated from aquatic animals and the environment have developed resistance to polymyxin B, carbapenems (imipenem and meropenem), cefotaxime, amoxicillin-clavulanic acid, aztreonam, and tetracycline [21]. Another study concentrated on the resistance against widely used antibiotics, including chloramphenicol, florfenicol, and oxytetracycline, in aquaculture [20]. They 
detected that over $90 \%$ of the isolates were resistant to the above-mentioned three antibiotics; however, almost all of the isolates were susceptible to trimethoprime-sulphonamide. This same pattern was observed in the human clinical isolates through the SENTRY Antimicrobial Surveillance Program conducted from 1997 to 2001 [35]. More recently, trimethoprime-sulphonamide has been considered to be the most potent antibiotic against Chryseobacterium $[15,36]$. However, the C. cucumeris SKNUCL01 isolated in this study was only susceptible to piperacillin/tazobactam, ceftazidime, and cefepime, while being resistant to trimethoprim/sulfamethoxazole, levofloxacin, and ciprofloxacin, which were formerly considered as effective treatments. The antibiotic resistance of this strain can be explained by the activity of MBLs and the efflux pump. Through the CDT, the presence of MBLs was elucidated using EDTA, an MBL inhibitor, which shows a significant increase in the inhibition zone of cefotaxime and cefepime. In addition, the MICs of piperacillin, imipenem, minocycline, and ceftazidime against C. cucumeris SKNUCL01 could be decreased by treatment with the efflux pump inhibitor. Previous reports showed that the efflux pump is an antibiotic resistance mechanism in Chryseobacterium and Flavobacterium, a closely related organism to Chryseobacterium, isolated from fish [20,37]. Michel et al. [20] suggested that the antibiotic (phenicols) resistance of Chryseobacterium was related to the efflux pump. More recently, Clark et al. [37] reported the MIC of antibiotics other than phenicols, such as erythromycin, levofloxacin, linezolid, and norfloxacin, which can be affected by the efflux pump in the Flavobacterium.

To elucidate the antibiotic resistance mechanism, we performed genetic screening. The FOX, bla $\mathrm{GES}, b l a_{\mathrm{IND}}, b l a_{\mathrm{KPC}}, b l a_{\mathrm{OXA}-48}$, and $b l a_{\mathrm{VIM}}$ genes, which are well known for conferring resistance to carbapenems, were examined first [38-44]. Then, the $b l a_{\mathrm{IND}}$ was screened for the presence of the enzyme that hydrolyzes the cephalosporins. However, the results were negative. Thus, we finally conducted screening for the $\beta$-lactamase genes previously reported from the Chryseobacterium genus such as $b l a_{\mathrm{CIA}}$ [45], and bla ${ }_{\mathrm{CGA}}$ [46], which showed negative results based on PCR. Further, we performed an efflux pump screen using the following primer sets: AcrAB-TolC set for tetracyclines or fluoroquinolones resistance; CmeABC set for tetracyclines; MexAB-OprD, MexCD-OprJ, and MexXY-OprN sets for $\beta$-lactams, fluoroquinolones, and tetracyclines. However, the genetic screening for the efflux pump also showed negative results as their activity did not exactly parallel those of the previously documented efflux pumps [47-49].

Using the inhibitors, we verified that MBLs and the efflux pump may be involved in the antibiotic resistance mechanism of C. cucumeris SKNUCL01. Inversely, this means that inhibitors such as EDTA, generally used for reducing heavy metals in aquaculture, could possibly be used as a synergistic agent of antibiotics. Although the antibiotic resistance-associated genes harbored by C. cucumeris SKNUCL01 have not been clearly proven, we focused on the characteristics of this organism as an opportunistic pathogen and provided clues against the multiple resistance Chryseobacterium outbreak.

\section{Materials and Methods}

\subsection{Ethical Statement}

The procedures involving animals were approved by the Institutional Animal Care and Use Committee (IACUC) of Seoul National University (SNU-190228-2), and the experiments were performed in accordance with approved guidelines.

\subsection{Bacterial Isolates and Culture Condition}

About 50-day-old moribund loaches (M. anguillicaudatus) with suspected columnaris were observed in a local aquaculture farm located in Gyeong-gi province, South Korea. Fish that showed lethargic activity, loss of appetite, and skin infection were collected. The skin lesions showed ulceration, loss of the epidermis, and fungus-like white patches. The natural mortality was less than $1 \%$; however, increased mortality was observed on the farm for several weeks, and the cumulative mortality surged to $10 \%$. Some of these fish were brought to our aquatic-animal facility (Laboratory of Aquatic Biomedicine, Seoul National University) and divided into two groups: therapy and observation groups. 
The moribund fish in the therapy group were treated with oxytetracycline hydrochloride $(50 \mathrm{mg} / \mathrm{L})$ for 5 days, followed by erythromycin $(25 \mathrm{mg} / \mathrm{L})$ for 12 hours by the immersion method. Bacteria were recovered from the skin lesions, liver, and spleen of the observation group. The skin lesions on the diseased fish were washed with sterile phosphate-buffered saline to minimize contamination and inoculated on tryptic soy agar (TSA, BD). The surfaces of the liver and spleen were sterilized with a $70 \%$ alcohol swab, and the sections were inoculated on TSA. After an overnight culture $(\sim 18 \mathrm{~h})$ at $25^{\circ} \mathrm{C}$, yellow and shiny colonies with a distinct smell were predominantly observed on the culture plates. The colonies were randomly picked and streaked onto TSA. After recovering single colonies, the culture was stored in glycerol at $-80^{\circ} \mathrm{C}$. The bacterial strains were cultured on TSA at $25^{\circ} \mathrm{C}$.

\subsection{Histological Analysis of the Skin Lesion}

The fish showing severe skin ulceration and lethargic activity were sacrificed immediately. The normal and ulcerative skin samples were preserved and fixed in neutral-buffered formalin (10\%), dehydrated with ethanol, and embedded in paraffin blocks. Then, the blocks were sectioned and stained using hematoxylin and eosin. The specimens were analyzed with light microscopy and digitally scanned by Xenos Inc. (Korea).

\subsection{Identification of Isolated Bacterial Strains}

To identify the isolates, Gram staining, biochemical tests using the VITEK 2 system, and 16S rRNA gene sequencing were performed. The gram staining was conducted with Color Gram 2 (bioMérieux, Craponne, France) following the manufacturer's instructions. The isolated bacteria were subjected to biochemical identification using the VITEK 2 system. A single colony was suspended in $3 \mathrm{~mL}$ of $0.45 \%$ saline solution and the turbidity was adjusted to a $0.5 \mathrm{McFarland}$ standard. The VITEK 2 GN card was then inoculated with the bacterial suspension. For the $16 \mathrm{~S}$ rRNA gene analysis, the genomic DNA of the bacteria was extracted by a conventional heat method [50]. In brief, $1 \mathrm{~mL}$ of overnight bacterial cultures were centrifuged $\left(12,000 \times g, 4{ }^{\circ} \mathrm{C}\right)$ and re-suspended in $100 \mu \mathrm{L}$ of TE buffer, and then the solution was heated for $10 \mathrm{~min}$ at $100{ }^{\circ} \mathrm{C}$ and centrifuged again. The $16 \mathrm{~S}$ rRNA gene was amplified with the universal primer set 27F/1492R using the supernatant [51]. The 16S rRNA gene was sequenced at Macrogen (Seoul, Korea), and the sequences obtained were compared to identify the bacterial strains using BLAST and EzTaxon [52]. The obtained partial 16S rRNA sequence (1466 bp) was deposited in GenBank under the accession number MK280733. Alignment was conducted and the phylogenetic tree was constructed using the maximum-likelihood method, implemented in MEGA7 [53]; 1000 bootstrap replications were used to build the phylogenetic tree.

\subsection{Virulence of C. cucumeris SKNUCLO1 in Pond Loach}

To analyze the virulence of C. cucumeris SKNUCL01, a bath immersion with or without artificial abrasion and intraperitoneal (IP) injection was performed. In total, 500 healthy adult pond loaches (13-17 g) were obtained from another farm located in the Jeonbuk province, South Korea, and acclimated at $25{ }^{\circ} \mathrm{C}$ for 30 days before challenge in a recirculating aquaculture system. The fish were fed with commercial Tetra Bits Complete (Tetra, Germany) at $2 \%$ body weight daily. The fish were maintained in a $200 \mathrm{~L}$ fiber glass tank under a $12 \mathrm{~h}$ light/dark schedule. For the virulence study, 10 fish were randomly allocated per each group in the $2 \mathrm{~L}$ aquaria $(20 \times 45 \mathrm{~cm})$.

For the immersion challenge, the overnight bacterial culture was inoculated with $1000 \mathrm{~mL}$ of water to adjust the density to $2.0 \times 10^{7} \mathrm{CFU} / \mathrm{mL}$ and acclimated with aeration for $1 \mathrm{~h}$. Then, the pond loaches were immersed in bacterial water and normal water (control) for $1 \mathrm{~h}$ and $24 \mathrm{~h}$. For the artificial abrasion test, abrasion $(1 \times 0.5 \mathrm{~cm})$ was introduced beside the pectoral fin by removing the skin, using a scalpel with anesthesia by tricaine methanesulfonate $(500 \mathrm{mg} / \mathrm{L} ; \mathrm{pH} 7$ adjusted by sodium bicarbonate). Then, the pond loaches were immersed in bacterial water and normal water (control) for $1 \mathrm{~h}$. After immersion, the fish were returned to $2 \mathrm{~L}$ aquaria (10 fish per tank). 
To calculate the $\mathrm{LD}_{50}$, each dilution of bacterial solution was injected into the pond loach via the intraperitoneal route, according to the Miller and Tainter method [54]. Four different doses $\left(1.8 \times 10^{5}-1.8 \times 10^{8} \mathrm{CFU} /\right.$ fish) and PBS (control group) were administered under anesthesia using tricaine methanesulfonate, and the fish were returned to the $2 \mathrm{~L}$ aquaria (10 fish per tank). The mortality was recorded daily for 10 days post-challenge. Dead fish were removed once daily, and the presence of C. cucumeris in the dead fish was confirmed by culturing spleen samples.

At the end of the study, the fish were euthanized using tricaine methanesulfonate $(2500 \mathrm{mg} / \mathrm{L}$; $\mathrm{pH} 7$ adjusted using sodium bicarbonate), and the rearing water was sterilized with bleach to prevent the spread of C. cucumeris SKNUCL01, a multidrug-resistant fish pathogen.

\subsection{Biofilm Formation of C. cucumeris SKNUCL01}

To verify the biofilm-forming ability, C. cucumeris SKNUCL01 was cultured in 96-well polystyrene tissue culture microplates (Nunc, Roskilde, Denmark) without shaking, according to Snoussi et al. [34] with minor modifications. A $1 \%(\mathrm{v} / \mathrm{v})$ overnight culture was inoculated into tryptic soy broth with or without glucose $(1 \%)$, and then $200-\mu \mathrm{L}$ aliquots were distributed into each well. The total biomass of the biofilm was quantified at $30 \mathrm{~min}$ (control), $24 \mathrm{~h}$, and $48 \mathrm{~h}$ post-inoculation. The biofilms were stained with crystal violet solution (1\%) for $15 \mathrm{~min}$ and washed with phosphate-buffered saline. Then, stained crystal violet was recovered in a $200 \mu \mathrm{L}$ ethanol-acetone solution $(80: 20 \mathrm{v} / \mathrm{v})$, and the OD was measured at $595 \mathrm{~nm}$.

\subsection{Antibiotic Susceptibility Test}

The minimum inhibitory concentration (MIC) was determined using the VITEK AST-N212 susceptibility test card as per the manufacturer's protocol. Briefly, $1 \mathrm{~mL}$ of overnight-grown bacteria in Mueller-Hinton broth (MHB; Becton Dickinson) was washed with sterile $0.45 \%$ sodium chloride solution. The suspension was added to $3 \mathrm{~mL}$ of sterile $0.45 \%$ sodium chloride solution to achieve McFarland No. 0.5. Then, the VITEK AST card was filled with the suspension. All the MICs were confirmed with three independent replicates. The antibiotic susceptibility profiles for ampicillin/sulbactam, piperacillin, piperacillin/tazobactam, cefotaxime, ceftazidime, cefepime, aztreonam, imipenem, meropenem, amikacin, gentamicin, ciprofloxacin, levofloxacin, minocycline, tigecycline, and trimethoprim/sulfamethoxazole were evaluated in accordance with the breakpoints suggested by the CLSI guidelines [55]. The susceptibility test was confirmed using Escherichia coli (ATCC 25922; antibiotic susceptible indicator).

\subsection{Phenotypic Tests for Detection of $\beta$-Lactamases}

To evaluate the antibiotic resistance mechanisms, phenotypic tests were performed to detect the $\beta$-lactamases that hydrolyze the cephalosporins (ceftazidime, ceftriaxone, cefepime, and cefotaxime) and carbapenems (imipenem and meropenem). The overnight-grown C. cucumeris SKNUCL01 was adjusted to a turbidity of McFarland No. 0.5 and inoculated on the Muller-Hinton agar plate using a sterile cotton swab. In the CDT, two sets of antibiotic disks (mentioned above), with one set containing $10 \mu \mathrm{L}$ of $0.1 \mathrm{M}$ EDTA, were placed $25 \mathrm{~mm}$ apart, center to center. A difference in the inhibition zone ( $\geq 4 \mathrm{~mm}$, diameter) around the antibiotic EDTA disk compared to that of the antibiotic disk alone was interpreted as positive for an MBL [56]. In the DDST, amoxicillin-clavulanic acid disks (20/10 $\mu \mathrm{g})$ were placed $27 \mathrm{~mm}$, center to center, away from the above-mentioned antibiotic disks [57]. Enhancement of the inhibition zone by the $\beta$-lactam inhibitor was interpreted as positive. In the MHT, E. coli (ATCC 25922) adjusted to McFarland No. 0.5 was inoculated evenly on the Mueller-Hinton agar plate using a sterile cotton swab as described elsewhere [58]. After drying for $5 \mathrm{~min}$, the above-mentioned set of antibiotic disks were placed at the center of the plate, and C. cucumeris SKNUCL01 was streaked heavily from the edge of the disk to the periphery of the plate. The zone of inhibition from the indicator strain was examined for a clover-like indentation following the growth of $C$. cucumeris SKNUCL01. All three tests were interpreted after $20 \mathrm{~h}$ of incubation at $37^{\circ} \mathrm{C}$. 


\subsection{Effect of PABN on the MIC}

The effect of PA $\beta N$, an efflux pump inhibitor, on the MICs was determined using the VITEK AST-N212 susceptibility test card. Briefly, $1 \mathrm{~mL}$ of overnight-grown bacteria in MHB was washed with sterile $0.45 \%$ sodium chloride solution. The suspension was added to $3 \mathrm{~mL}$ of sterile $0.45 \%$ sodium chloride solution containing 0, 25, 50, or $100 \mu \mathrm{g} / \mathrm{mL}$ PA $\beta N$ (Sigma) to achieve McFarland No. 0.5. Then, the VITEK AST card was filled with the suspension. All the MICs were confirmed by three independent replicates. Four-fold or greater differences in MICs compared to the control were considered significant [37].

\subsection{Detection of Antibiotic Resistance-Related Genes}

To elucidate the antibiotic resistance mechanisms of $C$. cucumeris SKNUCL01, $\beta$-lactamase, and efflux pump genes were PCR screened. The DNA of the isolate was extracted as mentioned above. The presence of following genes- $\beta$-lactamases $\left(b l a_{\mathrm{CIA}-1}, b l a_{\mathrm{CGA}-1}, b l a_{\mathrm{FOX}}, b l a_{\mathrm{GES}}, b l a_{\mathrm{GIM}}, b l a_{\mathrm{IND}}\right.$, $b l a_{\mathrm{KPC}}, b l a_{\mathrm{OXA}-48}, b l a_{\mathrm{VIM}}$ ) and efflux pumps (AcrAB-TolC, CmeABC, MexAB-OprD, MexCD-OprJ, and MexXY-OprN) - were examined as described previously [39-50]. Shortly, the amplification was performed with $10 \mathrm{~min}$ of denaturation at $95^{\circ} \mathrm{C}$, followed by the 35 cycles of $1 \mathrm{~min}$ at $95^{\circ} \mathrm{C}, 1 \mathrm{~min}$ at annealing temperature (Table S2), and $2 \mathrm{~min}$ at $72{ }^{\circ} \mathrm{C}$ and a $10 \mathrm{~min}$ of extension at $72{ }^{\circ} \mathrm{C}$. All the primer sets used in this study are shown in Table S2.

\subsection{Statistical Analyses}

The one-way analysis of variance (ANOVA) with the Bonferroni post hoc test was performed to verify the statistical significance using SigmaPlot v12.0 (Systat Software, Inc. Chicago, IL, USA). The statistical significance was set at a P value under 0.05 .

\section{Conclusions}

In this study, we provide the first description of the recovery of $C$. cucumeris from a diseased pond loach (M. anguillicaudatus), an important food and medicinal animal in East Asia. This pathogen could infect the host through a wound, which is characteristic of opportunistic pathogens. The resistance of $C$. cucumeris SKNUCL01 was significantly high to antibiotics formerly considered as effective treatments, such as trimethoprim/sulfamethoxazole, levofloxacin, and ciprofloxacin. Moreover, the isolate was resistant to most of the third-generation cephalosporins and carbapenems tested. We further showed that MBLs and the efflux pump affect the antibiotic resistance of this strain. Although genetic studies are insufficient to clearly elucidate the antibiotic resistance mechanisms, EDTA or PA $\beta N$ could increase bacterial susceptibility to several antibiotics and thus provide a breakthrough for the aquaculture industry against multidrug-resistant Chryseobacterium infection.

Supplementary Materials: The following are available online at http://www.mdpi.com/2076-0817/9/5/397/s1: Table S1: biochemical profiles of C. cucumeris SKNUCL01 were compared with type strains. Table S2: primer sets and PCR conditions used in this study.

Author Contributions: Conceptualization, S.G.K. and S.C.P.; methodology, S.G.K. and S.W.K.; software, S.W.K. and S.B.L.:; validation, S.G.K. and S.S.G.; formal analysis, S.G.K. and J.K.; investigation, S.G.K.; resources, S.G.K., S.S.G., S.B.L., S.W.K., J.K., and S.C.P.; data curation, S.G.K. and S.C.P.; writing-original draft preparation, S.G.K. and J.K.; writing-review and editing, S.G.K., S.S.G., S.C.P.; visualization, S.G.K.; supervision, S.C.P.; project administration, S.C.P.; funding acquisition, S.C.P. All authors have read and agreed to the published version of the manuscript.

Funding: This research was funded by the Cooperative Research Program of the Center for Companion Animal Research of the Rural Development Administration, Republic of Korea, grant number PJ0139852020.

Conflicts of Interest: The authors declare no conflict of interest. 


\section{References}

1. Saito, K. Movement and spawning of several freshwater fishes in temporary waters around paddy fields. Jpn. J. Ecol. 1988, 38, 35-47.

2. Kim, J.O.; Shin, H.S.; Yoo, J.H.; Lee, S.H.; Jang, K.S.; Kim, B.C. Functional evaluation of small-scale pond at paddy field as a shelter for mudfish during midsummer drainage period. Korean J. Environ. Biol. 2011, 30, 37-42.

3. Zhang, H.; Lu, X.; Zhang, Y.; Ma, X.; Wang, S.; Ni, Y.; Chen, J. Bioaccumulation of organochlorine pesticides and polychlorinated biphenyls by loaches living in rice paddy fields of Northeast China. Environ. Pollut. 2016, 216, 893-901. [CrossRef] [PubMed]

4. You, L.; Zhao, M.; Regenstein, J.M.; Ren, J. In vitro antioxidant activity and in vivo anti-fatigue effect of loach (Misgurnus anguillicaudatus) peptides prepared by papain digestion. Food Chem. 2011, 124, 188-194. [CrossRef]

5. You, L.; Zhao, M.; Liu, R.H.; Regenstein, J.M. Antioxidant and antiproliferative activities of loach (Misgurnus anguillicaudatus) peptides prepared by papain digestion. J. Agric. Food Chem. 2011, 59, 7948-7953. [CrossRef]

6. Chowdhury, M.B.R.; Wakabayashi, H. A study on Flexibacter columnaris infection in loach, Misgurnus anguillicaudatus (Bleeker, Günther). J. Fish Dis. 1991, 14, 389-394. [CrossRef]

7. Zhang, X.J.; Yao, D.R.; Yan, B.L.; Bi, K.R.; Liang, L.G.; Qin, G.M. Identification of Vibrio cholerae as a causative bacterium for an ulcer disease of cultured loach Misgurnus anguillicaudatus in China. Afr. J. Microbiol. Res. 2012, 6, 2060-2070.

8. Jun, J.W.; Kim, J.H.; Gomez, D.K.; Choresca, C.H.; Han, J.E.; Shin, S.P.; Park, S.C. Occurrence of tetracycline-resistant Aeromonas hydrophila infection in Korean cyprinid loach (Misgurnus anguillicaudatus). Afr. J. Microbiol. Res. 2010, 4, 849-855.

9. Zhu, M.; Wang, X.R.; Li, J.; Li, G.Y.; Liu, Z.P.; Mo, Z.L. Identification and virulence properties of Aeromonas veronii bv. sobria isolates causing an ulcerative syndrome of loach Misgurnus anguillicaudatus. J. Fish Dis. 2016, 39, 777-781. [CrossRef]

10. Campbell, S.; Harada, R.M.; Li, Q.X. Chryseobacterium arothri sp. nov., isolated from the kidneys of a pufferfish. Int. J. Syst. Evol. Microbiol. 2008, 58, 290-293. [CrossRef]

11. Zamora, L.; Vela, A.I.; Palacios, M.A.; Domínguez, L.; Fernández-Garayzábal, J.F. First isolation and characterization of Chryseobacterium shigense from rainbow trout. BMC Vet. Res. 2012, 8, 77. [CrossRef] [PubMed]

12. Shahi, N.; Sharma, P.; Pandey, J.; Bisht, I.; Mallik, S.K. Characterization and pathogenicity study of Chryseobacterium scophthalmum recovered from gill lesions of diseased golden mahseer, Tor putitora (Hamilton, 1822) in India. Aquaculture 2018, 485, 81-92. [CrossRef]

13. Bernardet, J.F.; Vancanneyt, M.; Matte-Tailliez, O.; Grisez, L.; Tailliez, P.; Bizet, C.; Nowakowskie, M.; Kerouaulta, B.; Swings, J. Polyphasic study of Chryseobacterium strains isolated from diseased aquatic animals. Syst. Appl. Microbiol. 2005, 28, 640-660. [CrossRef] [PubMed]

14. Chang, Y.C.; Lo, H.H.; Hsieh, H.Y.; Chang, S.M. Identification, epidemiological relatedness, and biofilm formation of clinical Chryseobacterium indologenes isolates from central Taiwan. J. Microbiol. Immunol. Infect. 2015, 48, 559-564. [CrossRef]

15. Lambiase, A.; Del Pezzo, M.; Raia, V.; Sepe, A.; Ferri, P.; Rossano, F. Chryseobacterium respiratory tract infections in patients with cystic fibrosis. J. Infect. 2007, 55, 518-523. [CrossRef]

16. Alfouzan, W.; Dhar, R.; Al-Hashemi, H.; Al-Sweih, N.; Albert, M.J. Clinical and microbiological characteristics of Chryseobacterium spp. isolated from neonates in Kuwait. JMM Case Rep. 2014, 1, 1. [CrossRef]

17. Lin, Y.T.; Jeng, Y.Y.; Lin, M.L.; Yu, K.W.; Wang, F.D.; Liu, C.Y. Clinical and microbiological characteristics of Chryseobacterium indologenes bacteremia. J. Microbiol. Immunol. Infect. 2010, 43, 498-505. [CrossRef]

18. Omar, A.; Camara, M.; Fall, S.; Ngom-Cisse, S.; Fall, B.; Ba-Diallo, A.; Diop-Ndiaye, H.; Toure-Kane, C.; Mboup, S.; Gaye-Diallo, A. Chryseobacterium indologenes in a woman with acute leukemia in Senegal: A case report. J. Med. Case Rep. 2014, 8, 138. [CrossRef]

19. Didinen, B.I.; Onuk, E.E.; Öztürk, T.; Metin, S.; Meryem, Ö.Z.; Çayli, Ö.; Kubilay, A. First report of Chryseobacterium sp. from Koi (Cyprinus carpio) in Turkey. Isr. J. Aquacult.-Bamid 2016, 68. Available online: https://www.researchgate.net/publication/316996691_First_report_of_Chryseobacterium_sp_From_ koi_Cyprinus_carpio_in_Turkey (accessed on 16 May 2020). 
20. Michel, C.; Matte-Tailliez, O.; Kerouault, B.; Bernardet, J.F. Resistance pattern and assessment of phenicol agents' minimum inhibitory concentration in multiple drug resistant Chryseobacterium isolates from fish and aquatic habitats. J. Appl. Microbiol. 2005, 99, 323-332. [CrossRef]

21. Maravić, A.; Skočibušić, M.; Šamanić, I.; Puizina, J. Profile and multidrug resistance determinants of Chryseobacterium indologenes from seawater and marine fauna. World J. Microbiol. Biotechnol. 2013, 29, 515-522. [CrossRef] [PubMed]

22. Mielmann, A. Food spoilage characteristics of Chryseobacterium species. Master's Thesis, University of the Free State, Bloemfontein, South Africa, 2006.

23. Bekker, A. Growth and spoilage characteristics of Chryseobacterium species in milk. Master's Thesis, University of the Free State, Bloemfontein, South Africa, 2011.

24. Zheng, L.; Bae, Y.M.; Jung, K.S.; Heu, S.; Lee, S.Y. Antimicrobial activity of natural antimicrobial substances against spoilage bacteria isolated from fresh produce. Food Control 2013, 32, 665-672. [CrossRef]

25. Sharma, P.; Gupta, S.K.; Diene, S.M.; Rolain, J.M. Whole-genome sequence of Chryseobacterium oranimense, a colistin-resistant bacterium isolated from a cystic fibrosis patient in France. Antimicrob. Agents Chemother. 2015, 59, 1696-1706. [CrossRef] [PubMed]

26. Jeong, J.J.; Lee, D.W.; Park, B.; Sang, M.K.; Choi, I.G.; Kim, K.D. Chryseobacterium cucumeris sp. nov., an endophyte isolated from cucumber (Cucumis sativus L.) root, and emended description of Chryseobacterium arthrosphaerae. Int. J. Syst. Evol. Microbiol. 2017, 67, 610-616. [CrossRef] [PubMed]

27. Qin, L.; Zhu, M.; Xu, J. First report of Shewanella sp. and Listonella sp. infection in freshwater cultured loach, Misgurnus anguillicaudatus. Aquac. Res. 2014, 45, 602-608. [CrossRef]

28. Loch, T.P.; Faisal, M. Chryseobacterium aahli sp. nov., isolated from lake trout (Salvelinus namaycush) and brown trout (Salmo trutta), and emended descriptions of Chryseobacterium ginsenosidimutans and Chryseobacterium gregarium. Int. J. Syst. Evol. Microbiol. 2014, 64, 1573-1579. [CrossRef]

29. Pridgeon, J.W.; Klesius, P.H.; Garcia, J.C. Identification and virulence of Chryseobacterium indologenes isolated from diseased yellow perch (Perca flavescens). J. Appl. Microbiol. 2013, 114, 636-643. [CrossRef]

30. Ilardi, P.; Fernandez, J.; Avendano-Herrera, R. Chryseobacterium piscicola sp. nov., isolated from diseased salmonid fish. Int. J. Syst. Evol. Microbiol. 2009, 59, 3001-3005. [CrossRef]

31. Menanteau-Ledouble, S.; Karsi, A.; Lawrence, M.L. Importance of skin abrasion as a primary site of adhesion for Edwardsiella ictaluri and impact on invasion and systematic infection in channel catfish Ictalurus punctatus. Vet. Microbiol. 2011, 148, 425-430. [CrossRef]

32. Abraham, T.J.; Sarker, S.; Dash, G.; Patra, A.; Adikesavalu, H. Chryseobacterium sp. PLI2 and Aeromonas hydrophila co-infection in pacu, Piaractus brachypomus (Cuvier, 1817) fries cultured in West Bengal, India. Aquaculture 2017, 473, 223-227. [CrossRef]

33. Pan, H.J.; Teng, L.J.; Chen, Y.C.; Hsueh, P.R.; Yang, P.C.; Ho, S.W.; Luh, K.T. High protease activity of Chryseobacterium indologenes isolates associated with invasive infection. J. Mcrobiol. Immunol. Infect. 2000, 33, 223-226.

34. Snoussi, M.I.; Noumi, E.; Cheriaa, J.; Usai, D.; Sechi, L.A.; Zanetti, S.; Bakhrouf, A. Adhesive properties of environmental Vibrio alginolyticus strains to biotic and abiotic surfaces. New Microbiol. 2008, 31, 489-500.

35. Kirby, J.T.; Sader, H.S.; Walsh, T.R.; Jones, R.N. Antimicrobial susceptibility and epidemiology of a worldwide collection of Chryseobacterium spp.: Report from the SENTRY Antimicrobial Surveillance Program (1997-2001). J. Clin. Microbiol. 2004, 42, 445-448. [CrossRef]

36. Chen, F.L.; Wang, G.C.; Teng, S.O.; Ou, T.Y.; Yu, F.L.; Lee, W.S. Clinical and epidemiological features of Chryseobacterium indologenes infections: Analysis of 215 cases. J. Mcrobiol. Immunol. Infect. 2013, 46, 425-432. [CrossRef]

37. Clark, S.E.; Jude, B.A.; Danner, G.R.; Fekete, F.A. Identification of a multidrug efflux pump in Flavobacterium johnsoniae. Vet. Res. 2009, 40,1-10.

38. Barguigua, A.; El Otmani, F.; Talmi, M.; Reguig, A.; Jamali, L.; Zerouali, K.; Timinouni, M. Prevalence and genotypic analysis of plasmid-mediated $\beta$-lactamases among urinary Klebsiella pneumoniae isolates in Moroccan community. J. Antibiot. Res. 2013, 66, 11-16. [CrossRef]

39. Poirel, L.; Le Thomas, I.; Naas, T.; Karim, A.; Nordmann, P. Biochemical sequence analyses of GES-1, a novel class A extended-spectrum $\beta$-lactamase, and the class 1 integron In52 from Klebsiella pneumoniae. Antimicrob. Agents Chemother. 2000, 44, 622-632. [CrossRef] 
40. Mendes, R.E.; Kiyota, K.A.; Monteiro, J.; Castanheira, M.; Andrade, S.S.; Gales, A.C.; Pignatari, A.C.C.; Tufik, S. Rapid detection and identification of metallo- $\beta$-lactamase-encoding genes by multiplex real-time PCR assay and melt curve analysis. J. Clin. Microbiol. 2007, 45, 544-547. [CrossRef]

41. Bellais, S.; Poirel, L.; Leotard, S.; Naas, T.; Nordmann, P. Genetic diversity of carbapenem-hydrolyzing metallo- $\beta$-lactamases from Chryseobacterium (Flavobacterium) indologenes. Antimicrob. Agents Chemother. 2000, 44, 3028-3034. [CrossRef]

42. Wolter, D.J.; Khalaf, N.; Robledo, I.E.; Vázquez, G.J.; Santé, M.I.; Aquino, E.E.; Goering, R.V.; Hanson, N.D. Surveillance of carbapenem-resistant Pseudomonas aeruginosa isolates from Puerto Rican medical center hospitals: Dissemination of KPC and IMP-18 $\beta$-lactamases. Antimicrob. Agents Chemother. 2009, 53, 1660-1664. [CrossRef]

43. Beyrouthy, R.; Robin, F.; Cougnoux, A.; Dalmasso, G.; Darfeuille-Michaud, A.; Mallat, H.; Dabboussi, F.; Hamzé, M.; Bonnet, R. Chromosome-mediated OXA-48 carbapenemase in highly virulent Escherichia coli. J. Antimicrob. Chemother. 2013, 68, 1558-1561. [CrossRef]

44. Monteiro, J.; Widen, R.H.; Pignatari, A.C.; Kubasek, C.; Silbert, S. Rapid detection of carbapenemase genes by multiplex real-time PCR. J. Antimicrob. Chemother. 2012, 67, 906-909. [CrossRef]

45. Matsumoto, T.; Nagata, M.; Ishimine, N.; Kawasaki, K.; Yamauchi, K.; Hidaka, E.; Kasuga, E.; Horiuchi, K.; Oana, K.; Kawakami, Y.; et al. Characterization of CIA-1, an Ambler class A extended-spectrum $\beta$-lactamase from Chryseobacterium indologenes. Antimicrob. Agents Chemother. 2012, 56, 588-590. [CrossRef]

46. Bellais, S.; Naas, T.; Nordmann, P. Molecular and biochemical characterization of Ambler class A extended-spectrum $\beta$-lactamase CGA-1 from Chryseobacterium gleum. Antimicrob. Agents Chemother. 2002, 46, 966-970. [CrossRef]

47. Swick, M.C.; Morgan-Linnell, S.K.; Carlson, K.M.; Zechiedrich, L. Expression of multidrug efflux pump genes acrAB-tolC, mdfA, and norE in Escherichia coli clinical isolates as a function of fluoroquinolone and multidrug resistance. Antimicrob. Agents Chemother. 2011, 55, 921-924. [CrossRef]

48. Olah, P.A.; Doetkott, C.; Fakhr, M.K.; Logue, C.M. Prevalence of the Campylobacter multi-drug efflux pump (CmeABC) in Campylobacter spp. isolated from freshly processed turkeys. Food Microbiol. 2006, 23, 453-460. [CrossRef]

49. Murugan, N.; Malathi, J.; Therese, K.L.; Madhavan, H.N. Application of six multiplex PCR's among 200 clinical isolates of Pseudomonas aeruginosa for the detection of 20 drug resistance encoding genes. Kaohsiung J. Med. Sci. 2018, 34, 79-88. [CrossRef]

50. Dweba, C.C.; Zishiri, O.T.; El Zowalaty, M.E. Isolation and molecular identification of virulence, antimicrobial and heavy metal resistance genes in livestock-associated methicillin-resistant Staphylococcus aureus. Pathogens 2019, 8, 79. [CrossRef]

51. Lane, D.J. 16S/23S rRNA sequencing. In Nucleic Acid Techniques in Bacterial Systematics; Stackebrandt, E., Goodfellow, M., Eds.; John Wiley and Sons: Chichester, UK, 1991; pp. 115-175.

52. Chun, J.; Lee, J.H.; Jung, Y.; Kim, M.; Kim, S.; Kim, B.K.; Lim, Y.W. EzTaxon: A web-based tool for the identification of prokaryotes based on $16 \mathrm{~S}$ ribosomal RNA gene sequences. Int. J. Syst. Evol. Microbiol. 2007, 57, 2259-2261. [CrossRef]

53. Kumar, S.; Stecher, G.; Tamura, K. MEGA7: Molecular evolutionary genetics analysis version 7.0 for bigger datasets. Mol. Biol. Evol. 2016, 33, 1870-1874. [CrossRef]

54. Miller, L.C.; Tainter, M. Estimation of the ED50 and its error by means of logarithmic-probit graph paper. Proc. Soc. Exp. Biol. Med. 1944, 57, 261-264. [CrossRef]

55. Clinical and Laboratory Standards Institute. Performance Standards for Antimicrobial Susceptibility Testing: Twenty-Fourth Informational Supplement, M100-S24, 24th ed.; National Committee for Clinical Laboratory Standards (NCCLS): Wayne, PA, USA, 2014.

56. Franklin, C.; Liolios, L.; Peleg, A.Y. Phenotypic detection of carbapenem-susceptible metallo- $\beta$-lactamase-producing gram-negative bacilli in the clinical laboratory. J. Clin. Microbiol. 2006, 44, 3139-3144. [CrossRef] 
57. Polsfuss, S.; Bloemberg, G.V.; Giger, J.; Meyer, V.; Böttger, E.C.; Hombach, M. Practical approach for reliable detection of AmpC beta-lactamase-producing Enterobacteriaceae. J. Clin. Microbiol. 2011, 49, 2798-2803. [CrossRef]

58. Lee, K.; Kim, C.K.; Yong, D.; Jeong, S.H.; Yum, J.H.; Seo, Y.H.; Docquier, J.D.; Chong, Y. Improved performance of the modified Hodge test with MacConkey agar for screening carbapenemase-producing Gram-negative bacilli. J. Microbiol. Methods 2010, 83, 149-152. [CrossRef]

(C) 2020 by the authors. Licensee MDPI, Basel, Switzerland. This article is an open access article distributed under the terms and conditions of the Creative Commons Attribution (CC BY) license (http://creativecommons.org/licenses/by/4.0/). 